\title{
Phaleria macrocarpa (Scheff.) Boerl fruit aqueous extract enhances LDL receptor and PCSK9 expression in vivo and in vitro.
}

\begin{abstract}
ETHNOPHARMACOLOGICAL RELEVANCE: Phaleria macrocarpa (Scheff.) Boerl (Pm) has been shown to reduce cholesterol level in vitro and in vivo experiment. AIM OF THE STUDY: This study investigated the effects of Pm fruit on weight control and mechanistic basis of its anti-hypercholesterolemic effect in both in vivo and in vitro. MATERIALS AND METHOD: In the in vivo study, thirty six male Sprague Dawley were randomized to six groups. Five groups were induced into hypercholesterolemia by giving 3\% cholesterol enriched-diet for 52 days while one group acted as control. The rats were then treated with Pm extract $(0,20,30$ and $40 \mathrm{mg} / \mathrm{ml})$ or simvastatin for 84 days. The following parameters were determined: (1) body weight, (2) blood lipid profile (total cholesterol, triglyceride, HDL and LDL) and (3) hepatic LDL receptor (160 kDa and $120 \mathrm{kDa})$ and PCSK9 proteins. In the in vitro study, HepG2 cells were cultured in serum-free RPMI supplemented with $0.2 \%$ BSA with or without LDL and in the presence of Pm extract $(0,0.1,2,40$ and 1,000 $\mu \mathrm{g} / \mathrm{ml})$ or simvastatin $(4.60 \mu \mathrm{g} / \mathrm{ml})$ for $24 \mathrm{~h}$. The abundance of both LDL receptor and PCSK9 proteins and mRNA were investigated. RESULTS: Pm extract significantly $(\mathrm{P}<0.05)$ reduced body weight gain, total cholesterol, triglycerides, HDL LDL levels and upregulated hepatic LDL receptor as well as PCSK9 proteins of hypercholesterolemic rats. These results were supported by studies in HepG2 cells whereby Pm extract also significantly upregulated both LDL receptor and PCSK9 at protein and mRNA levels. CONCLUSION: This study enhances the potential usage of $\mathrm{Pm}$ fruit for controlling the body weight of obese people and for treating hypercholesterolemia.
\end{abstract}

Keyword: Phaelaria Macrocarpa; Hypercholesterolemia; Weight control. 